\title{
Birth of first foals through embryo transfer after artificial insemination using frozen semen in Japan
}

\author{
M A HANNAN ${ }^{1,4)}$, Shingo HANEDA ${ }^{1)}$, Kaishi MURATA ${ }^{1)}$, Shiori TAKEUCHI'), \\ Soon Hon $\mathrm{CHEONG}^{2)}$ and Yasuo $\mathrm{NAMBO}^{1,3)}$ \\ 1) Department of Clinical Veterinary Sciences, Obihiro University of Agriculture and Veterinary Medicine, \\ Hokkaido 080-8555, Japan \\ ${ }^{2)}$ Department of Clinical Sciences, College of Veterinary Medicine, Cornell University, NY 14853, USA \\ 3) United Graduate School of Veterinary Sciences, Gifu University, Gifu 501-1193, Japan \\ 4) Faculty of Veterinary and Animal Sciences, Gono University, Savar 1344, Dhaka, Bangladesh
}

\begin{abstract}
Until now, there have been no reports of foals born through embryo transfer after artificial insemination using frozen semen in Japan. The aims of this study were to develop a riding crossbred horse and evaluate the prospects of embryo transfer technology in multiplying horse population. In both donor and recipient mares, luteolysis was induced by the administration of $0.1 \mathrm{mg}$ Cloprostenol to synchronize the onset of estrus, and ovulation was induced by administering 2000 IU human chorionic gonadotropin (hCG) or $0.75 \mathrm{mg}$ Deslorelin. Frozen semen from an Irish Connemara pony stallion was used to breed a Hokkaido native pony mare by deep-horn artificial insemination (dose, $400 \times 10^{6}$ sperm). A non-surgical technique was used to collect embryos from the donor mare at day 7 post-ovulation and transfer them transcervically into the uterus of recipient mares $(n=4)$ immediately after collection. Weekly blood samples were collected from the recipients throughout pregnancy. A total of four embryos were recovered from seven collection attempts (57\% recovery) from a donor mare in a single breeding season. Three of the four transferred embryos maintained successful pregnancy and delivered a healthy live foal (75\% birth). A normal progesterone profile was observed throughout gestation in recipient mares. In conclusion, for the first time, to the best of our knowledge, this study describes the birth of foals through non-surgical transcervical embryo transfer in Japan after artificial insemination using frozen semen. We expect that this new crossbreed (Connemara pony $\times$ Hokkaido native pony) will be a good riding breed.
\end{abstract}

Key words: Artificial insemination, Embryo transfer, Foal born, Frozen semen, Hokkaido native pony

(J. Reprod. Dev. 66: 193-197, 2020)

E mbryo transfer refers to the recovery of an embryo from the reproductive tract of a donor mare and its transfer into the reproductive tract of a recipient mare, which ultimately carries the pregnancy until delivery. Using this technique, multiple foals can be produced in a year from a single valuable donor mare. Embryo transfer technique is also used to overcome donor mare's subfertility, especially from uterine pathology, such as fibrosis, and allows mares in athletic competition to donate embryos and remain their performance [1-3].

In 1972, the first successful equine embryo transfer was performed surgically after the natural mating of donors and consisted of the transfer of embryos between horses and donkeys [4]. The first successful horse offspring produced by embryo transfer technology was born in 1974, and Japan was the pioneer of this success [5]. In this study, the donor mares mated naturally and a cervical by-pass method was used for embryo transfer [5]. The first non-surgical

Received: September 19, 2019

Accepted: January 4, 2020

Advanced Epub: January 26, 2020

(C2020 by the Society for Reproduction and Development

Corresponding: Y Nambo (e-mail: ynambo@obihiro.ac.jp)

This is an open-access article distributed under the terms of the Creative Commons Attribution Non-Commercial No Derivatives (by-nc-nd) License. (CC-BY-NC-ND 4.0: https://creativecommons.org/licenses/by-nc-nd/4.0/) transcervical embryo transfer resulting in foal birth was reported in 1975 [6], and currently, routine embryo transfers are performed using a similar technique [7]. Artificial insemination was another technology introduced as a breeding tool together with embryo transfer technology. The use of these techniques has flourished and expanded rapidly in Europe and America over the last two decades [8-10]. However, until now, there have been no reports of foals born from embryo transfer after artificial insemination using frozen semen in Japan. Recently, in a preliminary study, we successfully transferred embryos from a Hokkaido native pony after artificial insemination using frozen semen [11]. In that study, the embryo development and progesterone profile in the recipient mares were monitored for up to 35 days of gestation. In the present study, we aimed to observe the birth of the foals and their development up to eight weeks post-birth. Moreover, the progesterone profiles in recipient mares were monitored throughout the pregnancy.

The horse population in Japan has declined in recent decades, which is a threat to the riding industry. To produce ideal riding horses for the Hokkaido region of Japan, a cross between the Japanese Hokkaido native ponies, which are very calm and can survive well in cold weather, and Connemara ponies, which have a good temperament and are renowned for being excellent riding horses, was selected for their respective traits. We expect that a crossbred Connemara pony and Hokkaido native pony will produce a new ideal riding 
horse breed. The application of embryo transfer technology would assist in increasing the productivity of foals from elite mares and indirectly increase the horse population in Japan. Therefore, our objectives were to develop a riding crossbred horse and evaluate the prospects of embryo transfer technology in multiplying the horse population in Japan.

Both the donor and recipients had a single ovulation in all cases. The size of the ovulatory follicle was $3.2-4.0 \mathrm{~cm}$, and there were no occurrences of hemorrhagic follicles. A total of four embryos were recovered from seven collection attempts (57\% recovery) from a donor mare in a single breeding season (Fig. 1). Two embryos were at early blastocyst (Fig. 1A and 1D), one at hatched blastocyst (Fig. 1B), and one at blastocyst (Fig. 1C) stages at collection. All four embryos were assessed morphologically and were of excellent or good grade. The images of embryos in Figs. 1A and 1B were taken from our previous report [11]. Three of the four transferred embryos maintained successful pregnancy and resulted in the delivery of a healthy live foal (75\% birth). One embryo (Fig. 1D) that did not establish pregnancy could not be identified even during the first transrectal ultrasound check five days after transfer.

Photographs of each foal with their surrogate mothers are presented in Fig. 2A-C. All three foals together with their biological mother are pictured in Fig. 2D.

Delivery method, newborn sex, first standing time, initiation of suckling, birth weight, and body weight eight weeks after delivery in the three individual foals are presented in Table 1. All three foals were born spontaneously and stood 32, 50, and $62 \mathrm{~min}$ after birth and suckled from their surrogate mothers within 40 min after standing. After eight weeks, they had each gained approximately $75 \mathrm{~kg}$ in body weight. The gestational period was 358, 342, and 335 days for recipient \# 1, 2, and 3, respectively. All recipients showed good mothering behavior and normal lactation.

The plasma progesterone concentrations of the three recipient mares from the day of ovulation until delivery are shown in Fig. 3. The formation of the total supplementary corpus luteum (CL) number was 5, 5, and 2 in recipient mares \# 1,2, and 3, respectively. At ovulation, progesterone levels were below $1 \mathrm{ng} / \mathrm{ml}$ in all recipient mares and a sharp increase occurred at week 1 , followed by a slow decrease. A second rise occurred at week 6 and peaked at about week 10 , then gradually declined and reached a lower level at around week 26. Thereafter, a low level was maintained before the final rise approximately four weeks before delivery.

Although Japan is the pioneer of producing the first foal in the world through embryo transfer after the natural mating of donor mares with stallions in 1974 [5], there have been no reports of foals born through embryo transfer after artificial insemination in this country.
We recently reported a successful non-surgical embryo transfer [11], but in that study, pregnancy was only monitored for 35 days of gestation. Here, we report foals born through embryo transfer after artificial insemination using frozen semen for the first time in Japan.

The major factors that influence the embryo recovery rate from a donor mare are age and fertility of the donor, semen type and quality, recovery date, ovulation number, and clinical expertise [3, $7,10]$. A lower embryo recovery rate is typically observed for mares inseminated with frozen semen compared to insemination with fresh or cooled semen $[7,10,12]$. In the present study, the embryo recovery rate from a Hokkaido native pony after artificial insemination using frozen semen was $57 \%$, which is higher than the previously reported rate (about $40 \%$ ) using the same type of semen [7, 10]. We carried out artificial insemination using the deep-horn technique, which facilitates semen being deposited close to the uterotubal junction, which may have enhanced fertilization to a greater degree than in previous studies $[7,10]$ where conventional artificial insemination techniques were used. It has been reported that depositing semen at the uterotubal junction increases the number of spermatozoa in the ipsilateral oviduct, which presumably increases the pregnancy rate [13]. However, we only used one donor for embryo recovery; thus, the present rate may not be the conclusive embryo recovery rate from Hokkaido native ponies. Further studies with a larger number of donor mares conducted over several breeding seasons are required to conclusively identify the standard embryo recovery rate of our program.

The present results show a 75\% pregnancy and foaling rate after non-surgical transcervical embryo transfer. Pregnancy rates after non-surgical transcervical embryo transfer from several commercial embryo transfer programs were summarized and a rate of between $65.2 \%$ and $85.9 \%$ was found [7]. Therefore, the achieved pregnancy or foaling rate in this study was within the average range.

The present study introduced a new crossbred (Hokkaido native pony $\times$ Connemara pony) to Japan. All foals were born healthy and showed good development during the neonatal period, indicating that this new crossbreed is well-adapted to this region. Moreover, the initial trial by this study showed a good foaling rate; thus, we are optimistic that the developed crossbreed will possess better traits and their number may be increased rapidly through embryo transfer programs in coming years.

Progesterone is a key hormone for establishing and maintaining pregnancy [14]. In the present study, progesterone levels were detectable throughout the pregnancies in the embryo-transferred recipient mares, and the secretory profiles were in accordance with previously reported progesterone levels in pregnant mares [15-17]. However, we noticed an apparent higher peak in progesterone concentration

Table 1. Delivery method, sex, first time standing, initiation of suckling, birth weight, and weight eight weeks after delivery in three foals resulting from embryo transfer after artificial insemination using frozen semen in a Hokkaido native pony mare

\begin{tabular}{lcccccc}
\hline Foal ID & Delivery method & Sex & $\begin{array}{c}\text { First time standing } \\
(\mathrm{min})\end{array}$ & $\begin{array}{c}\text { Suckling initiation } \\
(\mathrm{min})\end{array}$ & $\begin{array}{c}\text { Birth weight } \\
(\mathrm{kg})\end{array}$ & $\begin{array}{c}\text { Weight } 8 \text { weeks after } \\
\text { delivery }(\mathrm{kg})\end{array}$ \\
\hline \#A & Spontaneous & Female & 50 & 63 & 38.2 & 112 \\
\#B & Spontaneous & Male & 62 & 70 & 45.3 & 129 \\
\#C & Spontaneous & Female & 32 & 72 & 40.8 & 107 \\
\hline
\end{tabular}



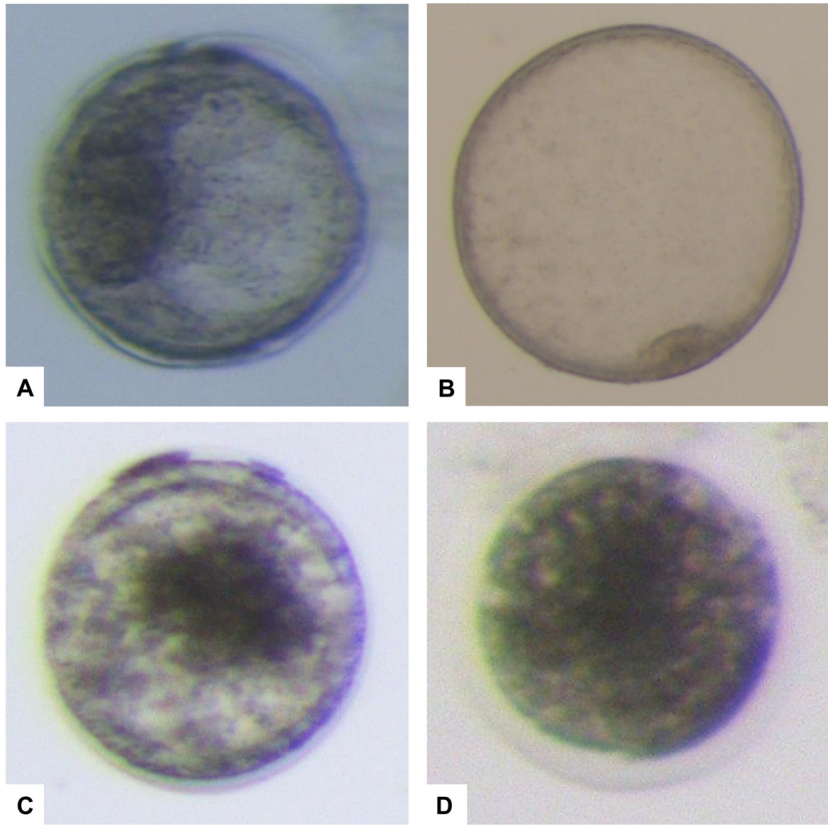

Fig. 1. Photomicrograph of embryos collected from a Hokkaido native pony seven days after artificial insemination using the frozen semen of an Irish Connemara pony stallion in a single breeding season. Two embryos were at the early-blastocyst (A and D), one was at hatched blastocyst (B), and one was at blastocyst (C) stages at collection. compared to previous studies [18, 19], which may be due to a higher incidence of supplementary CL formation in the present study. The average supplementary CL formation in pregnant mares in the present study was $4.0 \pm 1.0$, whereas only $1.9 \pm 0.2$ supplementary CL per pregnant mare was previously reported [20].

In conclusion, this study produced the first foals through nonsurgical transcervical embryo transfer after artificial insemination using frozen semen in Japan. The resulting crossbreed (Connemara pony $\times$ Hokkaido native pony) may be a good riding breed. The embryo transfer technology may be extremely useful for the rapid growth of the horse population in Japan.

\section{Methods}

\section{Animals}

A Hokkaido native pony (6-year-old) was used as the embryo donor, and two crossbred (Hokkaido native pony $\times$ Haflinger) and two purebred Hokkaido native pony mares (all aged 9 to 13 years) were used as recipients. The mares were maintained at the Horse Research Farm, Obihiro University of Agriculture and Veterinary Medicine. The horses were kept in a pasture attached to a roofed shelter and were fed hay, compressed hay (Hokkaido Horse Feed, Hokkaido, Japan), and Stamm 30 (Hallway Feeds, Lexington, KY, USA). The study was approved by the Animal Welfare and Ethics Committees of Obihiro University of Agriculture and Veterinary Medicine. All horses were in good health throughout the study.
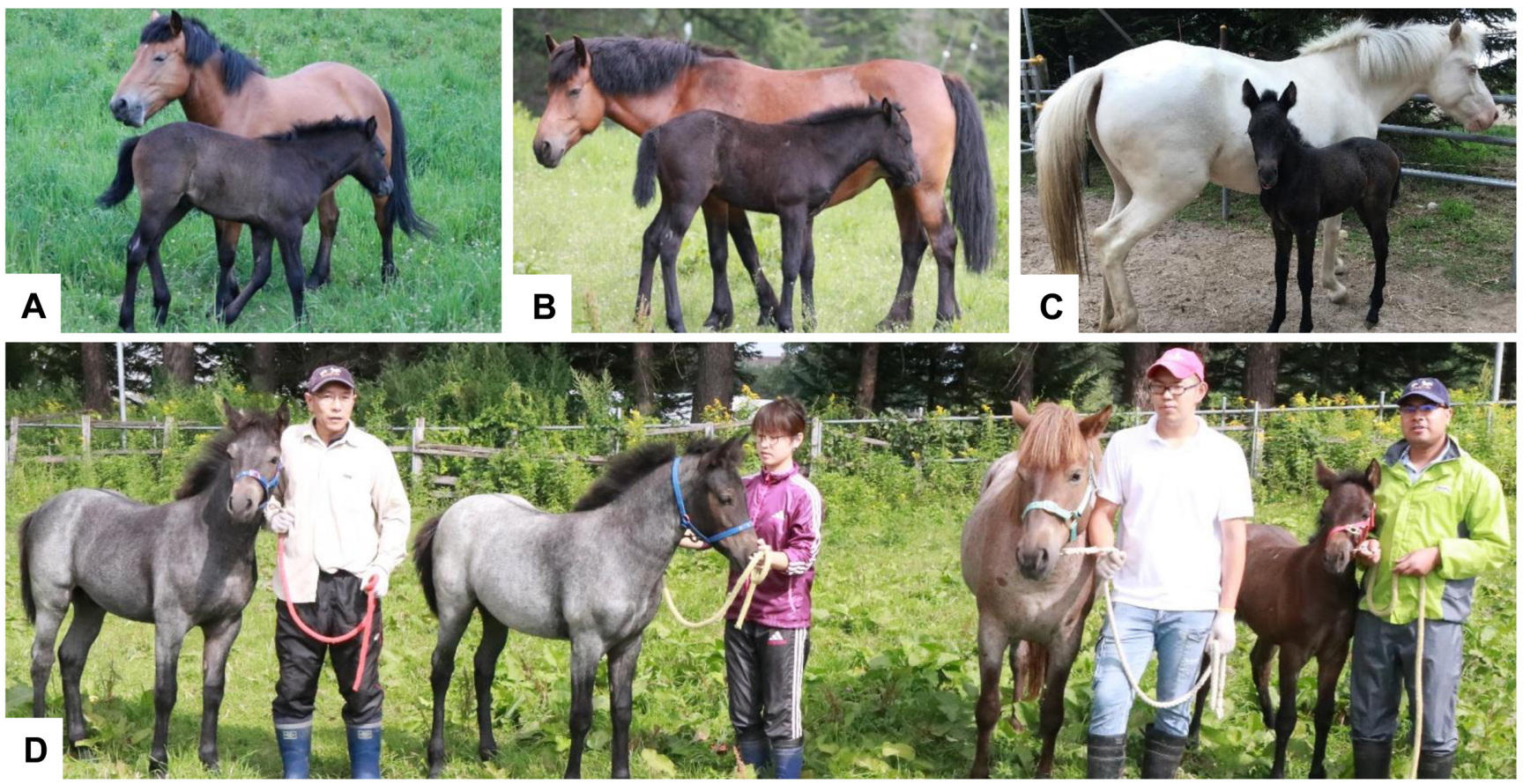

Fig. 2. Photograph of each foal with their surrogate mother (A-C). The ages of the foals A (colt), B (filly), and C (filly) are 44 , 45 , and 8 days, respectively. These are the first foals ever produced in Japan through embryo transfer after artificial insemination using frozen semen. All three foals together with their original dam (D); here the ages of foals A, B, and C were 121, 122, and 54 days, respectively. 


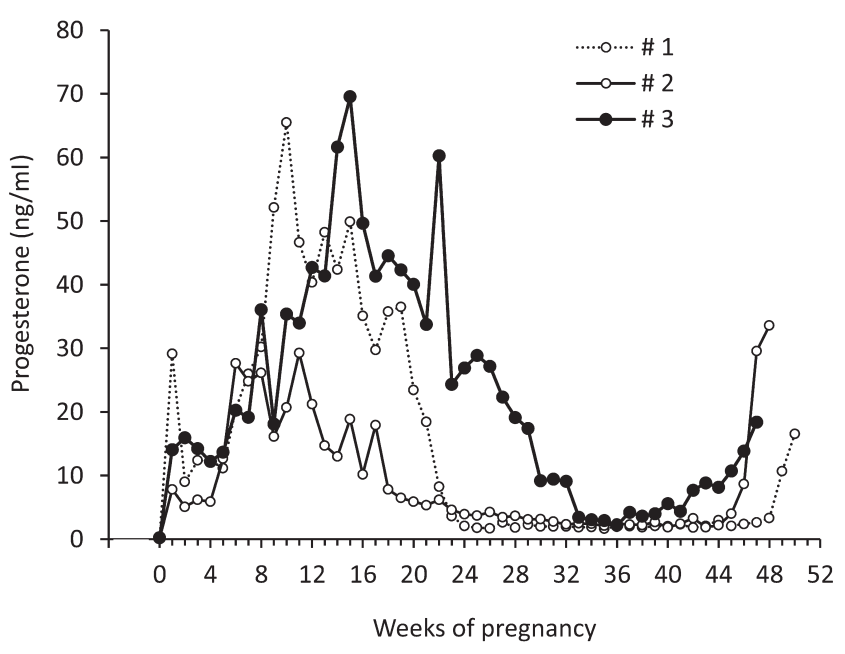

Fig. 3. Plasma progesterone profiles in three individual recipient mares throughout gestation. Progesterone levels were detected at the day of ovulation followed by weekly until delivery.

\section{Ultrasound examination and estrus synchronization}

A transrectal ultrasound (Hitachi Aloka, Tokyo, Japan) equipped with a $7.5 \mathrm{MHz}$ linear array transducer was used to evaluate the reproductive tract of the mares weekly from December 2017. Once the mares were close to the end of the vernal transition in early spring 2018, they were monitored daily to confirm the exact date of ovulation. The first ovulation of the season was allowed to occur spontaneously and was not taken into account for artificial insemination or embryo transfer. In both donor and recipient mares, luteolysis was induced by intramuscular administration of $0.1 \mathrm{mg}$ Cloprostenol (a prostaglandin $\mathrm{F}_{2 \alpha}$ analogue) (Planate ${ }^{\mathrm{R}}$, Nagase Medicals, Hyogo, Japan) during the mid-luteal phase to synchronize the onset of estrus. Ovulation in the donor mare was induced by administering 2,000 IU human chorionic gonadotropin (hCG) (Gonatropin ${ }^{\mathrm{R}}$, Asuka Animal Health, Tokyo, Japan) or $0.75 \mathrm{mg}$ gonadotropin-releasing hormone (GnRH) (Deslorelin, Boothwyn Pharmacy, Boothwyn, PA, USA) once the mare had a dominant follicle that was at least $35 \mathrm{~mm}$ in diameter with concurrent uterine edema of at least grade 3 from a scale of 0 (no edema) to 5 (large edema). Ovulation in the recipient mares was also induced similarly to maintain the acceptable recipient-ovulation synchrony window of one day before to three days after the donor mare.

\section{Artificial insemination}

A deep-horn artificial insemination technique using frozen semen from an Irish Connemara pony stallion (body weight, $473 \mathrm{~kg}$; insemination dose, $400 \times 10^{6}$ sperms with $50 \%$ post-thaw progressive motility) was used to breed the donor mare approximately $32 \mathrm{~h}$ after administration of hCG or GnRH. An $815 \mathrm{~mm}$ long, flexible, deep-insemination catheter for mares (IMV Technologies, L'Aigle, France) was inserted through the cervix and the tip of the insemination catheter was guided to the tip of the uterine horn ipsilaterally to the dominant follicle by transrectal palpation. A stylet was used to push the straw into the catheter and then push the straw's plug to release the semen. On one occasion, the donor mare ovulated spontaneously; and in that cycle, the mare was bred post-ovulation at approximately $24 \mathrm{~h}$ after the previous ultrasound examination.

Embryo recovery and transfer, as well as pregnancy diagnosis

A non-surgical procedure was used to collect the embryo from the uterine lumen of the donor mare at day 7 post-ovulation. The fresh embryos were transferred (within 20 min after collection) transcervically (non-surgical) into the uterus of the recipient mares. We have described embryo recovery and transfer previously in greater detail [11]. Five days after embryo transfer, pregnancy was diagnosed by transrectal ultrasonographic monitoring of the uterus.

\section{Blood sampling}

Blood samples were collected into a heparinized vacutainer (Terumo, Tokyo, Japan) by jugular venipuncture from recipient mares on the day of ovulation (day 0), followed by weekly until delivery. The blood samples were immediately placed on ice and centrifuged $\left(3,000 \mathrm{rpm}\right.$ for $12 \mathrm{~min}$ at $\left.4^{\circ} \mathrm{C}\right)$ to separate the plasma. The plasma samples were stored at $-30^{\circ} \mathrm{C}$ and thawed just prior to the progesterone assay, which was performed using a commercially available enzyme immunoassay kit (ST AIA-PACK PROG II, Tosoh Bioscience, San Francisco, CA, USA). The minimum detectable concentration for progesterone was $0.06 \mathrm{ng} / \mathrm{ml}$, and the inter assay CV was $0.58 \%$.

\section{Acknowledgments}

We are thankful to Kenichi Urata, Yuriko Hayashi, Sohei Wachi, and Yasuyuki Itami for assisting in horse management. This study was supported by the Livestock Promotional Subsidy from the Japan Racing Association.

\section{References}

1. Campbell ML. Embryo transfer in competition horses: Managing mares and expectations. Equine Vet Educ 2014; 26: 322-327. [Medline] [CrossRef]

2. Panzani D, Rota A, Pacini M, Vannozzi I, Camillo F. One year old fillies can be successfully used as embryo donors. Theriogenology 2007; 67: 367-371. [Medline] [CrossRef]

3. Squires EL, McCue PM, Vanderwall D. The current status of equine embryo transfer Theriogenology 1999; 51: 91-104. [Medline] [CrossRef]

4. Allen WR, Rowson LEA. Transfer of ova between horses and donkeys. In: Proceedings of the seventh international congress on animal reproduction and artificial insemination; 1972; Munich, Germany. p. 484-487.

5. Oguri N, Tsutsumi Y. Non-surgical egg transfer in mares. J Reprod Fertil 1974; 41: 313-320. [Medline] [CrossRef]

6. Allen WR, Rowson LEA. Surgical and non-surgical egg transfer in horses. J Reprod Fertil Suppl 1975; 23: 525-530. [Medline]

7. McCue PM, Squires EL. Equine Embryo Transfer 2015; 1st ed., CRC Press.

8. Herrera C, Morikawa MI, Bello MB, von Meyeren M, Centeno JE, Dufourq P, Martinez MM, Llorente J. Setting up equine embryo gender determination by preimplantation genetic diagnosis in a commercial embryo transfer program. Theriogenology 2014; 81: 758-763. [Medline] [CrossRef]

9. Jacob JCF, Haag KT, Santos GO, Oliveira JP, Gastal MO, Gastal EL. Effect of embryo age and recipient asynchrony on pregnancy rates in a commercial equine embryo transfer program. Theriogenology 2012; 77: 1159-1166. [Medline] [CrossRef]

10. Panzani D, Rota A, Marmorini P, Vannozzi I, Camillo F. Retrospective study of factors affecting multiple ovulations, embryo recovery, quality, and diameter in a commercial equine embryo transfer program. Theriogenology 2014; 82: 807-814. [Medline] [CrossRef]

11. Hannan MA, Haneda S, Itami Y, Wachi S, Saitoh T, Cheong SH, Nambo Y. Successful embryo transfer from Hokkaido native pony after artificial insemination with frozen 
semen. J Vet Med Sci 2019; 81: 241-244. [Medline] [CrossRef]

12. Miller CD. Optimizing the use of frozen-thawed equine semen. Theriogenology 2008; 70: 463-468. [Medline] [CrossRef]

13. Rigby SL, Derczo S, Brinsko S, Blanchard T, Taylor T, Forrest D, Varner D. Oviductal sperm numbers following proximal uterine horn or uterine body insemination. In: Proceedings of the American Association of Equine Practitioners 2000; 46: 332-334.

14. Mendelson CR. Minireview: fetal-maternal hormonal signaling in pregnancy and labor. Mol Endocrinol 2009; 23: 947-954. [Medline] [CrossRef]

15. Holtan DW, Nett TM, Estergreen VL. Plasma progestagens in pregnant mares. J Reprod Fertil Suppl 1975; 23: 419-424. [Medline]

16. Squires EL, Wentworth BC, Ginther OJ. Progesterone concentration in blood of mares during the estrous cycle, pregnancy and after hysterectomy. J Anim Sci 1974; 39: 759-767. [Medline] [CrossRef]

17. Allen WR. Luteal deficiency and embryo mortality in the mare. Reprod Domest Anim 2001; 36: 121-131. [Medline] [CrossRef]

18. Ginther OJ. Endocrinology of pregnancy. In: Reproductive biology of the mare. Basic and applied aspects; Second edition, Cross Plains, Wisconsin, USA 1992: 419-426.

19. Willmann C, Schuler G, Hoffmann B, Parvizi N, Aurich C. Effects of age and altrenogest treatment on conceptus development and secretion of LH, progesterone and eCG in early-pregnant mares. Theriogenology 2011; 75: 421-428. [Medline] [CrossRef]

20. Boeta M, Zarco L. Luteogenic and luteotropic effects of eCG during pregnancy in the mare. Anim Reprod Sci 2012; 130: 57-62. [Medline] [CrossRef] 